\title{
Simplified treatment for impacted upper canines: a four-year follow-up
}

\author{
Tratamento simplificado para caninos superiores impactados
}

Irla Mello de OLIVEIRA ${ }^{1}$

Rogério Dal Bello FIGUEIRAS²

Renata Cristina Faria Ribeiro CASTRO ${ }^{1}$

\begin{abstract}
In the literature, there are several treatment options for the correction of upper canines, from extractions to surgical procedures followed by traction. Presenting a clinical case with a new treatment proposal for the traction of impacted upper canines, aiming at simplifying the orthodontic mechanics and establishing a satisfactory result with less biological demand. 18-year old female presenting with a palatally impacted upper left canine with increased mesial inclination, bilateral Class I occlusal relationship and harmonic facial profile. The surgical traction of the canine tooth was performed with an upper fixed arch wire, modified by a TMA spring, with subsequent set up of the fixed appliance for orthodontic correction. The achieved results were satisfactory, providing suitable aesthetic and function to the case, showing good root parallelism and intercuspation, ensuring stability to treatment after four years of the appliance removal.
\end{abstract}

Indexing terms: Cuspid. Maxilla. Corrective orthodontics.

\section{RESUMO}

Na literatura, existem várias opções de tratamento para a correção de caninos superiores impactados, desde extrações até procedimentos cirúrgicos seguidos de tracionamentos. Apresentar um caso clínico com uma nova proposta de tratamento para o tracionamento de caninos superiores impactados, visando simplificar a mecânica ortodôntica e estabelecer um resultado satisfatório com menor danos biológicos. Paciente do sexo feminino, 18 anos apresentando um canino superior esquerdo palatalmente impactado com maior inclinação mesial, relação bilateral oclusal de Classe I e perfil facial harmônico. A tração cirúrgica do dente canino foi realizada com um fio de arco superior modificado por uma mola TMA, com a instalação subseqüente do aparelho fixo para correção ortodôntica. Os resultados obtidos foram satisfatórios, proporcionando estética e função adequadas ao caso, mostrando bom paralelismo radicular e intercuspidação, garantindo estabilidade ao tratamento após quatro anos de remoção do aparelho.

Termos de indexação: Dente canino. Maxila. Ortodontia corretiva.

\section{INTRODUCTION}

The upper canine teeth present the second highest risk of impaction, losing only to the third molars ${ }^{1}$, following a long and sinuous eruption pathway, from their formation until their eruption into the oral cavity. Furthermore, the lateral incisor root guides its eruption into the oral cavity². The most common etiological factors that cause impaction are arch length discrepancy, late retention of the deciduous teeth, abnormal position of the dental germ, occurrence of alveolar fissure, ankyloses, cyst or neoplastic formation, root laceration, iatrogenesis and idiopathic conditions such as multifactorial sources ${ }^{2,3-5}$. The upper canine buccal shift is related to the reduction of the intercanine distance, the upper arch crowding and the hypodivergent skeletal pattern ${ }^{6}$. In $2 \%-3 \%$ of the Caucasian population, this tooth fails to erupt and deviate from its normal eruption path, showing an ectopic eruption ${ }^{2,7}$.

Early diagnosis allows a better treatment prognosis, with more satisfactory results, avoiding possible impaction issues as root resorption of the adjacent teeth, ankyloses of the impacted tooth or cyst formation ${ }^{1,8}$. On the other hand, the treatment prognosis will depend on the position and the height of such tooth considering the adjacent teeth, the patient age, the horizontal positioning and the buccolingual inclination of the canines ${ }^{9-10}$. This research study has investigated the positioning of the upper canines when compared to the lateral incisors, evaluating the panoramic $x$-rays of 28 patients in the mix dentition, aiming at predicting its impaction on the palate. The authors have classified the upper incisors area concluding that, when the upper canine cusps overstep the mesial of the lateral

\footnotetext{
${ }^{1}$ Faculdade São Leopoldo Mandic, Programa de Pós-Graduação em Odontologia. Rua José Rocha Junqueira, 13, Swift, 13045-755, Campinas, SP, Brasil. Correspondência para / Correspondence to: RCFR CASTRO. E-mail: <renata.castro@slmandic.edu.br>.

${ }^{2}$ Hospital Central da Aeronáutica. Rio de Janeiro, RJ, Brasil.
} 
incisors, such teeth will be palatally impacted ${ }^{2,11-12,}$

The interceptive treatment protocol, successfully seen in more than $50 \%$ of the ectopic canine cases, was proposed by Baccetti et al. ${ }^{13}$, in which rapid maxillary expansion was performed in a sample comprising 60 subjects, presenting mix dentition and palatally impacted canines with no transverse deficiency of the upper arch. The sample was divided into two groups, with and without rapid maxillary expansion, and the authors have observed that in $65 \%$ of the treated cases the upper canines did not erupted, demonstrating the efficiency of the treatment. There are several options to treat impacted canines such as the interceptive treatment using headgear appliances, with and without extractions of the deciduous canine ${ }^{11-12}$. Baccetti et al. ${ }^{11}$ have conducted a study evaluating 70 subjects with average age of 11 years, mix dentition and palatally impacted canines, being divided in three groups: with extractions of the deciduous canines; with extractions of the deciduous canines and use of headgear appliances; and a control group. These patients were seen over an 18-month period through the evaluation of panoramic $\mathrm{x}$-rays (T1 and T2). Results have shown that the group treated with extractions of the deciduous canines presented a $65 \%$ success rate when compared to the control group. The group treated with extractions of the deciduous canines along with the use of headgear appliances presented an $87 \%$ improvement rate considering the eruption of the permanent canines.

Additional studies support the extraction of the corresponding deciduous tooth and wait for the eruption of the permanent tooth ${ }^{5,14-15}$, as described by Giulio et al. ${ }^{15}$ who have evaluated 59 patients with impacted canines at the end of the mix dentition and average age of 10 years. Such patients were divided into two groups: group with extraction of the deciduous canines and group with extraction of both the deciduous upper canines and the deciduous upper first molars. The ectopic canines and bicanines angulation was measured analyzing the panoramic x-rays in TO and after 18 months. The authors have concluded that dual extractions were more efficient in improving the intraosseous positioning of the ectopic canine. Moreover, additional corrective options should also be considered to treat impacted canines when dental extractions are performed ${ }^{16-17}$ and when no extractions are considered $^{18-19}$. Garib et al. ${ }^{16}$ have described the clinical case of a 15-year old female subject, presenting a Class III malocclusion, an impacted upper canine in an unfavorable position and severe reabsorption of the central and lateral left incisors. Rapid maxillary expansion was performed, in addition to extractions of the lower first premolars (to compensate for the class III) and the upper canines, due to its unfavorable prognosis to traction and, also, aiming at achieving aesthetics and smile symmetry. The authors have also emphasized the importance of early diagnosis, as extraction and incisors resorption could have been avoided.

Based on this literary context, this case report aims at presenting a simple option for the traction of palatally impacted upper canines with unfavorable inclination, applying a modified palatal arch and TMA spring to make it easier for the application of the orthodontic mechanics. Despite being an adult patient, the ectopia of the canine tooth did not cause damage to the adjacent teeth, showing angulation that made it possible to have a more conservative treatment, with no exodontics.

\section{CASE REPORT}

An 18-year old female patient sought for treatment at the Orthodontic Department at the Aeronautics Hospital in which the main complaint was the deciduous upper canine hold in the dental arch. Clinically, the patient presented a Class I molar relationship; the right canine in occlusal key; tooth 63 retained in the dental arch, with increased mass on the palate, around the left canine area; good tooth alignment; generalized diastema, in the anterior region; and matching midlines (figure 1).

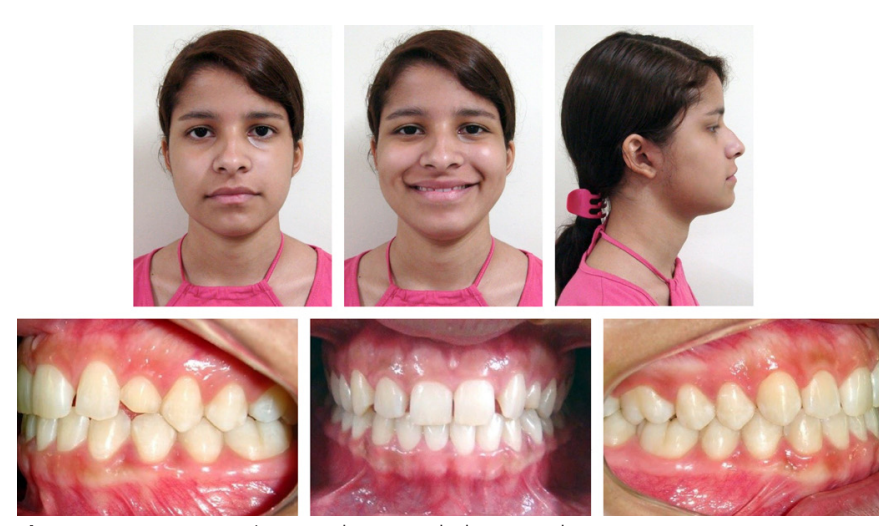

Figure 1. Pretreatment intra and extraoral photographs

Anamnesis was performed as well as $\mathrm{x}$-rays and intra and extra-oral photographs were taken, along with study models, to determine the correct diagnosis for the case (figures 1 and 2). Good proportionality was seen on the facial thirds and facial profile, as well as a passive lip sealing. The cephalometric analysis indicated measurements 
within the norms and a retroinclined position of the upper and lower incisors. In addition, an occlusal x-ray was taken, identifying the horizontal positioning of tooth 23 , which was mesially inclined, overstepping the roots of the upper central and lateral incisors (figure 2).
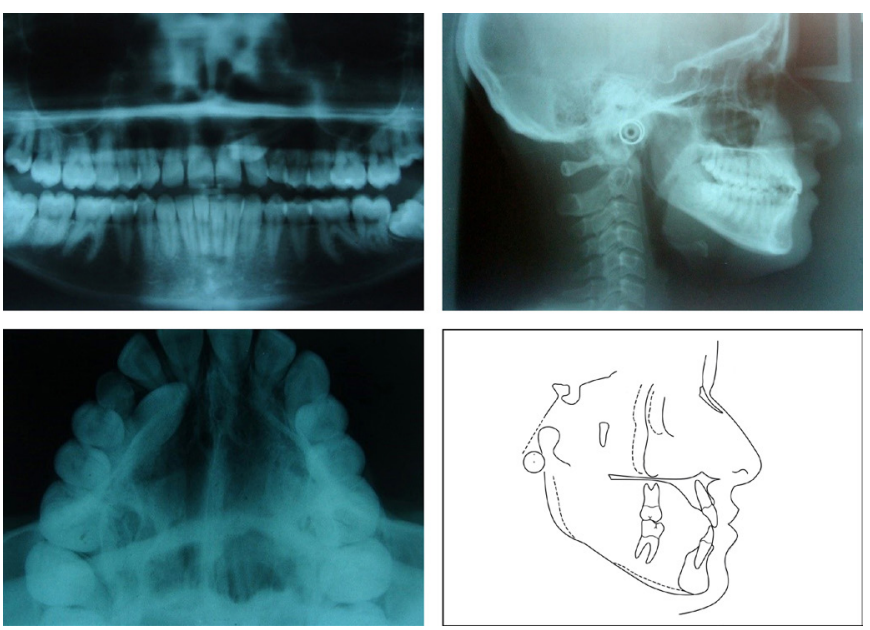

Figure 2. Pretreatment x-rays and cephalometric tracing

The goal of the orthodontic treatment was to extract the deciduous tooth hold on the dental arch and traction tooth 23, keeping the dental arches coordinated, reestablishing the adequate function and aesthetics to the patient.

Three treatment options were presented to the patient. The first one consisted in extracting the deciduous tooth, tractioning the impacted permanent tooth. This treatment approach was more conservative, however, more complex, once the impacted canine was in an unfavorable position to traction. The second option consisted in extracting both the deciduous and the permanent canines, followed by an implant set up, which would make the orthodontic treatment simpler and faster. The third treatment option was extracting both the deciduous and the permanent canines, mesializing the teeth of second quadrant.

The patient's choice was to extract the deciduous tooth followed by traction of the impacted canine, as it was a more conservative treatment approach. Furthermore, the good intercuspation and the dental arches coordination were favorable to apply the traction mechanics, avoiding anchorage loss on the posterior teeth.

Edgewise brackets, .022coordinatibracket slot, were set up on the patient to align and level the upper and lower dental arches. Additionally, the patient was asked to use high-pull headgear appliance at sleep time, in order to avoid anchorage loss on the posterior segment when applying the orthodontic mechanics. During the initial aligning and leveling stages, .014", .016" and .018" steel arch wires engaged to treat the case. And, to create space and traction tooth 23, a nickel-titanium open coil spring was inserted between teeth 22 and 24 . After five months that the orthodontic corrective treatment was started, at the end of the aligning stage, an .01818et up on the el arch wire was engaged on the upper arch and tooth 63 was extracted, besides the surgical exposure of the impacted tooth.

Soon after the surgical expansion of the canine tooth, a fixed palatal arch wire modified by a TMA spring (figure 3) was set, using a 018was set, using a tal arch wire modified by a TMA spring (ch and tooth 63 was extracted, besides the surgical exposure of the impacted toocanine tooth towards the dental arch (figure 3). After three months that traction was started, tooth 23 was very close to the dental arch. At this moment, the TMA spring incorporated to the fixed arch wire was cut and, then, buttons were bonded on the buccal and ligual surfaces of the canine tooth to rotate it through a binary. Finally, with the canine already positioned in the dental arch, a realignment was performed and the case was finalized (figure 3).

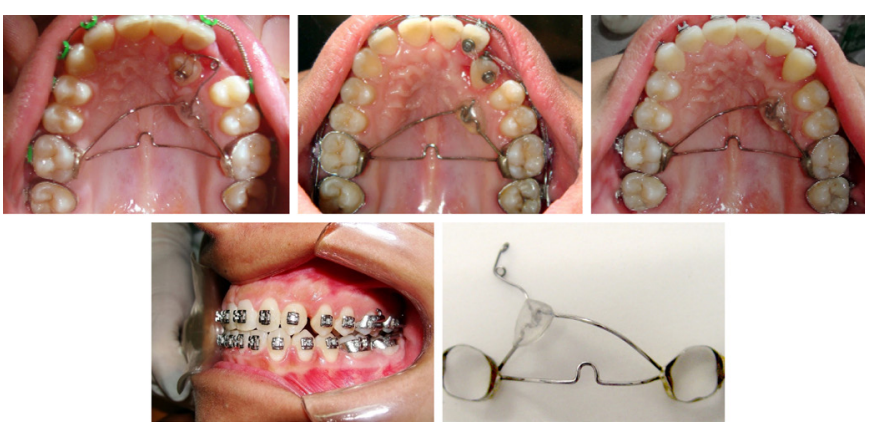

Figure 3. Pretreatment progressive intraoral photographs.

After four years of treatment and evaluation of the occlusal results, it can be seen a good stability of the orthodontic treatment, with the establishment of the occlusal guides, the correct alignment and correction of the dental arches, adequate fit of the canine and the molar teeth, perfect root parallelism and good facial profile (figures 4 and 5, chart 1). The treatment option chosen to treat this case, which was tractioning the impacted canines, has shown to be an adequate option, presenting excellent aesthetic and functional results, meeting the patientate fit of the ntporated to, the mechanics applied using a fixed palatal arch modified by a TMA spring has shown to be effective, providing a faster and safe correction of the canine tooth. 

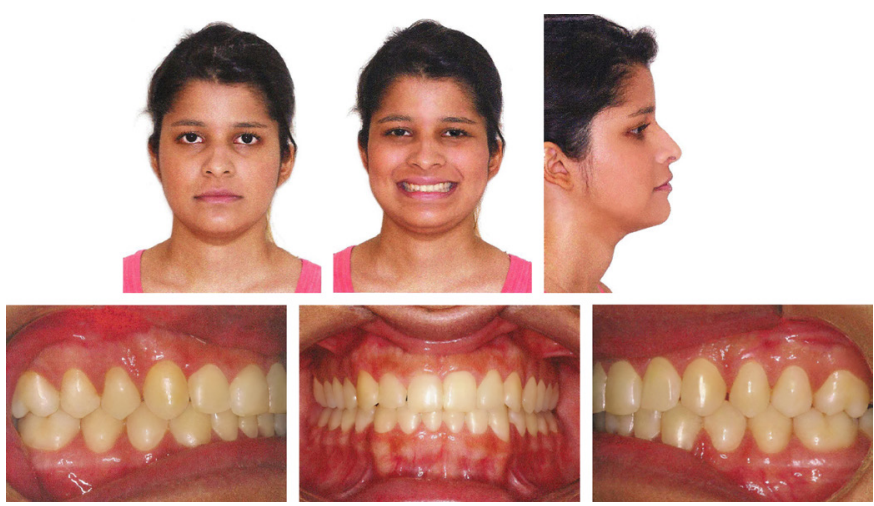

Figure 4. Post-treatment intra and extraoral photographs.
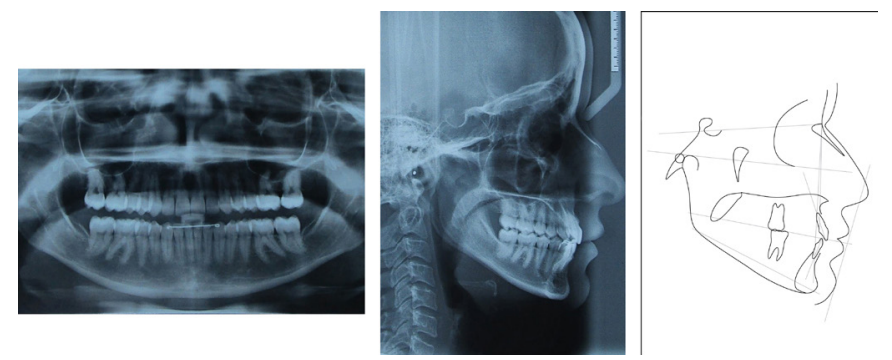

Figure 5. Post-treatment $x$-rays and cephalometric tracing
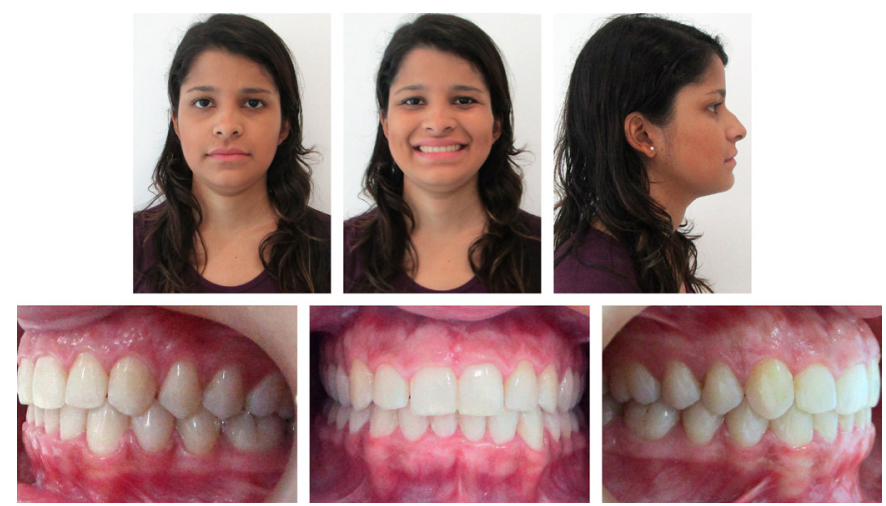

Figure 6. Intra and extraoral photographs four year after the end of the orthodontic treatment.

Chart 1. Comparison of the cephalometric variables at the beginning and end of the orthodontic treatment.

\begin{tabular}{lll}
\hline Variables & Initial & Final \\
\hline FMA & $30^{\circ}$ & $33^{\circ}$ \\
FMIA & $68^{\circ}$ & $59^{\circ}$ \\
IMPA & $81^{\circ}$ & $87^{\circ}$ \\
SNA & $84^{\circ}$ & $82^{\circ}$ \\
SNB & $83^{\circ}$ & $80^{\circ}$ \\
ANB & $1^{\circ}$ & $2^{\circ}$ \\
Go-Gn.SN & $32.97^{\circ}$ & $32^{\circ}$ \\
OcI.SN & $13^{\circ}$ & $14^{\circ}$ \\
$1-N A$ & $1.37 \mathrm{~mm}$ & $2.5 \mathrm{~mm}$ \\
$1: N A$ & $14^{\circ}$ & $21^{\circ}$ \\
$1-N B$ & $1.52 \mathrm{~mm}$ & $2.66 \mathrm{~mm}$ \\
$1: N B$ & $19^{\circ}$ & $21^{\circ}$ \\
\hline
\end{tabular}

\section{DISCUSSION}

Besides its aesthetic importance, the canines also have a protective function on the dental arch through the occlusal guides, resulting in a mutually protected occlusion ${ }^{20-21}$.

One way to avoid the ectopic eruption of the canines is performing a selective extraction of the deciduous canines, as this procedure enables a normal eruption of the palatally displaced canine ${ }^{14-15,22}$. Furthermore, the use of headgear appliances, with cervical traction, increases the chances of treatment success, regardless if the treatment was conducted with or without extractions of the deciduous canines, 11-12. In this case report, the pulled canine was impacted in sector $\mathrm{Vl}$, according to the classification

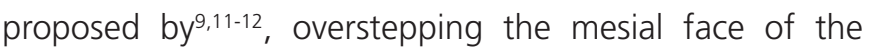
lateral incisor, increasing the risk of complications such as resorption of the lateral incisors ${ }^{11-12,16,23}$. However, in this case report, the patient was an adult subject, being necessary to traction the palatally impacted canine and exodontics of the corresponding deciduous tooth, resulting in a faster treatment with favorable prognosis. The device model used in this case report was a fixed palatal arch wire, aiming at obtaining anchorage to traction, and a .018ent when applying the orthodontic to the acrylic to move the impacted canine towards the dental arch (figure 3). The case report described by Sukh, Sing and Tandon ${ }^{19}$, treating buccaly impacted upper canines, applying a segmented dental arch mechanics and a .017plying a segmented dental arch mechanics and a a faster treatment with favorable progn

In addition, the traction of the palatally impacted upper canines, with no extractions, was performed using a K-9 modified spring, with a .017ormed using arch wire with two arms, aiming at bringing the impacted canine to the dental $\operatorname{arch}^{18}$, with extractions of the upper first premolar teeth, engaging a $.016 \mathrm{t}$ Niti arch wire over the .019.019per first premolar teeth, engaging a .016t wicanine tooth ${ }^{17}$. The traction performed in this current study have lasted five months, resulting in aesthetics, function and periodontal quality, while similar studies took up to 10 months to perform the same procedure ${ }^{19}$ and $15-$ 20 months in total treatment time ${ }^{17-18}$.

After four years that the orthodontic treatment was finished (figure 6), aiming at verifying the stability of the treated case, the patient was reassessed and it was verified that the occlusal guides were in place, as well as the correct root parallelism, good alignment with no 
interproximal spaces and matching midlines. In addition, there was also a perfect match of the functional occlusal guides, reflecting a good cusp/fossa posterior occlusion, and suitable overjet and overbite

\section{CONCLUSION}

Although the patient underwent orthodontic treatment at a later age, with the upper left canine in an unfavorable position, there were no severe consequences commonly seen in these cases, such as incisors resorption and need to extract the permanent teeth. It is necessary to perform the individual diagnosis of the impacted canines, since the success rate is proper to each clinical case. The

\section{REFERENCES}

1. Lai CS, Suter VGA, Katsaros C, Bornstein MM. Localization of impacted maxillary canines and root resorption of neighbouring teeth: a study assessing the diagnostic value of panoramic radiographs in two groups of observers. Eur J Orthod. 2014 Aug;36(4):450-6. doi: 10.1093/ejo/cjt074

2. Naoumova J, Kurol J, Kjellberg H. A systematic review of the interceptive treatment of palatally displaced maxillary canines. Eur J Orthod. 2011 Apr;33(2):143-9. doi: 10.1093/ejo/cjq045

3. Bishara SE. Impacted maxillary canines: a review. Am J Orthod. 1992;101(2):159-71.

4. Becker A, Gillis I, Shpack N. The etiology of palatal displacement of maxillary canines. Clin Orthod Res. 1999;2(2):62-6.

5. Litsas G.; Acar A. A review of early displaced maxillary canines: etiology, diagnosis and interceptive treatment. Open Dent J. 2011; 5: 39-47. 2011. doi: 10.2174/1874210601105010039

6. Mucedero M, Ricchiuti MR, Cozza P, Baccetti T. Prevalence rate and dentoskeletal features associated with buccally displaced maxillary canines. Eur J Orthod. 2013;35(3):305-9. doi: 10.1093/ ejo/cjr133

7. Thilander B, Myrberg N. The prevalence of malocclusion in Swedish school children. Scand J Dent Res. 1973;81(1):12-21.

8. Cernochova P, Krupa P, Izakovicova-Holla L. Root resorption assiciated with ectopically erupting maxillary permanent caninies. a computed tomography study. Eur J Orthod. 2011 Oct;33(5):483-91. doi: 10.1093/ejo/cjq085

9. Lindauer SJ, Rubenstein LK, Hang WM, Issacson RJ. Canine impaction identified early with panoramic radiographs. J Am Ass. 1992; 123: 91-97.

10. Pitt S.; Hamdan A.; Rock P. A treatment difficulty index for unerupted maxillary canines. Eur J Orthod. 2006;28(2):141-4. doi: 10.1093/ejo/cji068

11. Baccetti T, Leonardi M, Armi P. A randomized clinical study of two interceptive approaches to palatally displaced canines. Eur J Orthod. 2008 Aug;30(4):381-5. doi: 10.1093/ejo/cjn023 traction of the impacted canines, applying a modified palatal device, has shown to be a safe option to this type of treatment. Four years after the end of the orthodontic treatment, the biomechanics applied has shown to be efficient, simple and stable to treat such cases.

\section{Collaborators}

I, RCFR CASTRO, have supervised the writing of this article. IM OLIVEIRA has treated the clinical case and RDB FIGUEIRAS has supervised the student during the patient treatment.

12. Leonardi M, Armi P, Franchi L, Baccetti T. Two interceptive approaches to palatally displaced canines: a prospective longitudinal study. Angle Orthod. 2004;74(5):581-6.

13. Baccetti T, Mucedero M, Leonardi M, Cozza P. Interceptative treatment of palatal impaction of maxillary canines with rapid maxillary expansion: a randomised clinical trial. Am J Orthod Dentofacial Orthop. 2009 Nov;136(5):657-61. doi: 10.1016/j. ajodo.2008.03.019

14. Camilleri S, Scerri E. Transmigration of mandibular canines-a review of the literature and a report of five cases. Angle Orthod. 2003;73:753-2.

15. Giulio AB, Serena IP, Matteo Z, Ida M. Double vs single primary teeth extraction approach as prevention of permanent maxillary canines ectopic eruption. Pediatr Dent. 2010;32(5):407-12.

16. Garib DG, Janson G, Baldo TO, Santos PBD. Complications of misdiagnosis of maxillary canine ectopic eruption. Am J Orthod Dentofacial Orthop. 2012;142(2):256-63. doi: 10.1016/j. ajodo.2010.12.023..

17. Goel A, Loomba A, Goel P, Sharma N. Interdisciplinaty approach to palatally impacted canine. Natl Maxillofac Surg. 2010;1(1): 53-57. doi: 10.4103/0975-5950.69169

18. Shastri D, Nagar A, Tandon P. Alignment of palatally impacted canine with open window technique and modified K-9 spring. Contemp Clin Dent. 2014;5(2):272-274. doi: 10.4103/0976237X.132362

19. Sukh R, Singh GP, Tandon P. Interdisciplinary approach for the management of bilaterally impacted maxillary canines. Contemp Clin Dent. 2014;5(4):539-44. doi: 10.4103/0976-237X.142828

20. Chapokas AR, Almas K, Schincaglia G. The impacted maxillary canine: a porposed classification for surgical exposure. Oral Surg Oral Med Oral Pathol Oral Radiol. 2012;113(2):222-8. doi: 10.1016/j.tripleo.2011.02.025

21. Pokorny PH, Wiens JP, Litvar H. Occlusion for fixed prosthodontics: a historical perspective of the gnathological influence. J Prosthet Dent. 2008;99(4):299-313. doi: 10.1016/S00223913(08)60066-9 
22. Al-Nimri K.; Gharaibeh T. Space conditions and dental and occlusal features in patients with palatally impacted maxillary canines: an aetiological study. Eur J Orthod. 2005:27:461-465. doi: 10.1093/ejo/cji022
23. Ericson S, Kurol J. Radiographic examination of ectopically erupting maxillary canines. Am J Orthod Dentofacial Orthop. 1988;91:483-92. doi: 10.1016/0889-5406(87)90005-9

Received on: 29/6/2016

Final version resubmitted on: 1/11/2016

Approved on: 21/12/2016 